\title{
Membrane Properties Underlying the Firing of Neurons in the Avian Cochlear Nucleus
}

\author{
A. D. Reyes, ${ }^{1,2}$ E. W Rubel, ${ }^{2}$ and W. J. Spain ${ }^{2,3,4}$ \\ 'Department of Medical Genetics, ${ }^{2}$ Virginia Merrill Bloedel Hearing Research Center, and ${ }^{3}$ Department of Medicine \\ (Division of Neurology), University of Washington School of Medicine, Seattle, Washington 98195, and ${ }^{4}$ Seattle VA \\ Medical Center, Seattle, Washington 98108
}

\begin{abstract}
Neurons of the avian nucleus magnocellularis (NM) relay auditory information from the VIIIth nerve to other parts of the auditory system. To examine the cellular properties that permit NM neurons to transmit reliably the temporal characteristics of the acoustic stimulus, we performed wholecell recordings in neurons of the chick NM using an in vitro thin slice preparation. NM neurons exhibited strong outward rectification near resting potential; the voltage responses to depolarizing current steps were substantially smaller than to equivalent hyperpolarizing steps. Suprathreshold current steps evoked only a single action potential at the start of the step. In contrast, stimulation with trains of brief current pulses evoked repetitive firing that was phase-locked to the stimulus cycle. The number of action potentials evoked by the pulses during the train decreased with increasing stimulus rate. Voltage-clamp experiments revealed a rapidly activating, slowly inactivating, outward current with a threshold near $-65 \mathrm{mV}$. During depolarizing voltage steps, the outward current rose sigmoidally to a peak and then decayed slowly, reaching steady state within $5 \mathrm{sec}$. Application of $200 \mu \mathrm{M}$ 4-aminopyridine (4-AP) reduced the peak of the outward current by $84 \%$, leaving a small, persistent component. Under current clamp, application of $200 \mu \mathrm{M}$ 4-AP reduced the outward rectification and increased the amplitude and duration of the action potentials. Moreover, NM neurons could no longer sustain firing during high rates of stimulation with the current pulses: increased temporal summation of the potentials caused sufficient depolarization to inactivate the sodium conductance underlying the action potential. These results suggest that the outward current is necessary for NM neurons to transmit well-timed events reliably for the duration of an acoustic stimulus.
\end{abstract}

IKey words: nucleus magnocellularis, cochlear nucleus, action potential, phase-locking, whole-cell recording, potassium current, 4-aminopyridine]

\footnotetext{
Received Aug. 27, 1993; revised Mar. 4, 1994; accepted Mar. 15, 1994.

We thank Drs. K. Canady, R. Foehring, P. Schwindt, and R. Rubsamen for their valuable comments on this manuscript, and $R$. Lee for his technical assistance. This work was supported by a Department of VA Merit Review, the Virginia Merrill Bloedel Hearing Research Center, NIH Grants DC00395 and HD07391, and a Blethen Fellowship.

Correspondence should be addressed to Dr. Alex D. Reyes, Virginia Merrill Bloedel Hearing Research Center, RL-30, University of Washington, Seattle, WA 98195

Copyright (C 1994 Society for Neuroscience $0270-6474 / 94 / 145352-13 \$ 05.00 / 0$
}

The avian nucleus magnocellularis (NM) contains the secondorder auditory neurons that serve as a relay in the pathway responsible for sound localization in the azimuth. NM neurons arc innervated by VIIIth nerve fibers and project bilaterally to neurons of the nucleus laminaris (NL; Parks and Rubel, 1975; Rubel and Parks, 1975; Young and Rubel, 1983; Carr and Konishi, 1990). Differences in the times of arrival of sound to the two ears, which vary with location of sound, translate to differences in the arrival times of impulses to NL from the ipsilateral and contralateral NM (Overholt et al., 1992; Joseph and Hyson, 1993).

Precise information about the temporal characteristics of an acoustic stimulus is encoded in the phase-locked activity of NM neurons (Sullivan and Konishi, 1984; Carr and Konishi, 1990; Warchol and Dallos, 1990). During phase-locking, action potentials occur at some phase of the stimulus cycle with remarkably little jitter (Sullivan and Konishi, 1984; Carr and Konishi, 1990). NM neurons in chickens can phase-lock to stimuli with frequencies as high as $2 \mathrm{kHz}$ (Warchol and Dallos, 1990), while thosc in owls can phase-lock up to $9 \mathrm{kHz}$ (Sullivan and Konishi, 1984).

NM neurons have several physiological features that enhance their ability to relay temporal information to NL precisely and reliably. First, the synapse between the VIIIth nerve and NM neurons is very secure. Stimulation of a single VIIIth nerve fiber evokes synaptic potentials with amplitudes that can exceed 20 $\mathrm{mV}$ (Hackett et al., 1982; Jackson and Parks, 1982). The large synaptic potentials ensure that the firing of NM neurons is tightly coupled with the firing of VIIIth nerve fibers.

Second, the synaptic potentials are brief. Intracellular recordings in NM (Hackett et al., 1982; Jackson and Parks, 1982) and its mammalian homolog, the bushy cells of the anteroventral cochlear nucleus (AVCN; Oertel, 1983), show that, despite their large amplitudes, synaptic potentials have durations of only 1$6 \mathrm{msec}$. This is partly due to the rapid desensitization of AMPA receptors that results in brief synaptic currents (Raman and Trussell, 1992; Trussell et al., 1993) and partly due to active conductances that rapidly repolarize the synaptic potentials (Oertel, 1983; Manis and Marx, 1991). The rapid repolarization of the synaptic potentials is postulated to be important for preserving the temporal characteristics of the acoustic stimulus (Oertel, 1983; Wu and Oertel, 1984; Manis and Marx, 1991).

A third important feature is the ability of NM neurons to maintain firing for the duration of the acoustic stimulus. NM neurons in chickens can sustain discharge rates ranging from 110 to $480 \mathrm{~Hz}$ (Warchol and Dallos, 1990). This occurs though 
the extraordinarily large synaptic potentials arrive in NM at a rapid rate: if each action potential is triggered by a single synaptic potential, the arrival rate is at least equal to the neuron's discharge ratc. Morcover, because an NM neuron is innervated by 2-3 VIIIth nerve afferents (Hackett et al., 1982; Jackson and Parks, 1982) and because each fiber can discharge at a maximum sustained rate of approximately $400 \mathrm{~Hz}$ (Manley et al., 1991), synaptic potentials could arrive in NM neurons at rates as high as $800-1200 \mathrm{~Hz}$. The rapid arrival of large synaptic potentials is likely to cause a sustained, high level of depolarization that could inactivate the sodium conductance underlying the action potential (Hodgkin and Huxley, 1952). In order to maintain firing, NM neurons must therefore compensate for excessive depolarization.

This report concerns the membrane properties that permit NM neurons to maintain firing in the presence of rapidly occurring synaptic events. Whole-cell recordings were performed using a thin slice preparation (Edwards et al., 1989). Brief current pulses were injected through the recording electrode to produce voltage deflections that rescmble stimulus-cvoked synaptic potentials (Hackett et al., 1982; Jackson and Parks, 1982). The pulses were injected repetitively at rates comparable to the estimated arrival rates of synaptic potentials during acoustic stimulation, and the resultant firing documented. Injection of current pulses at regular intervals, while not incorporating the complexities of VIIIth nerve discharge patterns (Rose, 1967), provides a redsonable indication of how well NM neurons can respond to rapidly occurring synaptic potentials. The electrophysiological and pharmacological properties of underlying ionic conductances were then examined under voltage clamp. Finally, the role of an outward current in the firing of NM neurons was assessed by comparing the firing before and after the outward current was reduced with 4-aminopyridine.

Portions of this work have appeared in abstract form (Reyes et al., 1991, 1992).

\section{Materials and Methods}

Slice preparation. Whole-cell recordings were performed in neurons of chick NM. Chicks (1-5 d posthatch) were decapitated and a $1 \mathrm{~cm}$ section of the skull containing the brainstem was removed with a razor blade and quickly submerged in cooled $\left(4^{\circ} \mathrm{C}\right)$ artificial cerebrospinal fluid (ACSF). ACSF contained (in mM) $130 \mathrm{NaCl}, 26 \mathrm{NaH}_{2} \mathrm{CO}_{3}, 3 \mathrm{KCl}, 2$ $\mathrm{CaCl}_{2}, 2 \mathrm{MgCl}_{2}, 1.25 \mathrm{NaH}_{2} \mathrm{PO}_{4}$, and 10 dextrose. A $2 \mathrm{~mm}$ section of the brainstem containing NM was dissected and transferred to a Vibratome tissue slicer (TPI Inc., St. Louis, MO), where it was mounted on an agar block with cyanoacrylate glue and submerged in cooled ACSF. Ten 50-70 $\mu \mathrm{m}$ coronal slices were made and placed in separate compartments in a holding chamber filled with ACSF, maintained at $34^{\circ} \mathrm{C}$, and gassed with $95 \% \mathrm{O}_{2}$ and $5 \% \mathrm{CO}_{2}$ to maintain $\mathrm{pH}$ at 7.4 .

Whole-cell recordings. Individual slices were transferred to a $0.5 \mathrm{cc}$ recording chamber mounted on a Zeiss microscope and perfused with warmed $\operatorname{ACSF}\left(35-40^{\circ} \mathrm{C}\right)$ at a rate of approximately $1.5 \mathrm{ml} / \mathrm{min}$. Using a multiple valve system, the slices could be perfused with a variety of modified ACSFs containing one or several of the following: (1) $1 \mu \mathrm{M}$ tetrodotoxin (TTX), (2) $20 \mu \mathrm{M}-2 \mathrm{~mm}$ 4-aminopyridine (4-AP), and (3) 1-10 mM tetraethylammonium chloride (TEA) substituted in equimolar amounts for $\mathrm{NaCl}$. In some experiments, a nominally calcium-free solution was used in which either $2 \mathrm{~mm} \mathrm{MnCl}_{2}$, or $0.5 \mathrm{~mm}$ EGTA and 5 mM $\mathrm{MgCl}_{2}$ was substituted for $\mathrm{CaCl}_{2} . \mathrm{NaH}_{2} \mathrm{PO}_{4}$ was omitted to minimize precipitation of $\mathrm{MnCl}_{2}$. All chemicals were from Sigma Chemical Co. (St. Louis, MO)

The electrodes were drawn from $75 \mu$ l hematocrit tubing (VWR, San Francisco, CA) using a two-stage puller, coated with Polystyrene Q-dope (GC Electronics, Rockford, IL) to reduce stray capacitance, and the tips heat polished to DC resistances of 2-5 M . The electrode solution consisted of (in mM) 0.1 EGTA or BAPTA, $15 \mathrm{KCl}, 100 \mathrm{~K}$-gluconate, $5 \mathrm{MgCl}_{2}, 10 \mathrm{HEPES}, 4 \mathrm{Na}_{2}$ ATP, 0.1 leupeptin, 20 phosphocreatine, and $50 \mathrm{U} / \mathrm{ml}$ creatine phosphokinase. The osmolality was $290 \mathrm{mOsm}$ and the $\mathrm{pH}$ was adjusted to 7.2 with $\mathrm{KOH}$. All voltage traces and plots shown in figures were corrected for the measured junction potential of $-5 \mathrm{mV}$.

Individual cells were visualized using a $40 \times$ water-immersion lens and Nomarski optics. The electrode was guided onto the cell soma while applying positive pressure to prevent clogging. Upon contact with the cell, negative pressure was applied until a tight seal $(>1 \mathrm{G} \Omega$ ) was formed. Further negative pressure was applied until the underlying membrane was ruptured. Stable recordings could be maintained for up to $2 \mathrm{hr}$.

Current-clamp experiments were performed with an Axoclamp $2 \mathrm{~A}$ (Axon Instruments Inc., Foster City, CA) amplifier in bridge mode. Single-electrode voltagc-clamp experiments were performed with an Axopatch $200 \mathrm{~A}$ amplifier, which permitted series resistance compensation of approximately $95 \%$. Voltage and current traces were filtered at $5 \mathrm{kHz}$ and recorded on videotapes using pulse code modulation with a frequency response of $44 \mathrm{kHz}$. Data were digitized off line and stored on a computer for further analysis.

The times of occurrences of action potentials were identified with an amplitude window discriminator. Threshold for detection of action potential occurrences was set to approximately $60-75 \%$ of the action potential height. Construction of histograms and analysis of current traces were performed using routines written in Igor (Wavemetrics, Lake Oswego, OR)

Intracellular records of layer $\mathrm{V}$ cortical neurons from the cat sensorimotor cortex (see Fig. $3 B$ ) were from data collected in unrelated experiments. The surgical and rccording procedures are detailed in Spain et al. (1991).

All results are expressed as the mean \pm SD unless otherwise noted.

\section{Results}

Data were obtained from 101 cells in the rostral two-thirds of NM. Cells were accepted for analysis if a greater than $1 \mathrm{G} \Omega$ seal was obtained between the electrode and membrane prior to entering the whole-cell recording configuration, and the resting membrane potential was more negative than $-55 \mathrm{mV}$. Action potentials with durations less than $0.4 \mathrm{msec}$ and amplitudes greater than $35 \mathrm{mV}$ could be evoked from cells that met these criteria. None of the neurons discharged spontaneously.

\section{Properties of subthreshold responses}

Several measurements were taken near resting potential to characterize the subthreshold membrane properties of NM neurons. The resting membrane potential, measured from 47 cells, was $-63 \pm 4 \mathrm{mV}$. The membrane capacitance, measured under voltage clamp with the capacity compensator of the Axopatch $200 \mathrm{~A}$, was $14.7 \pm 2.4 \mathrm{pF}(n=18)$. The input resistance, taken as the slope of the linear portion of the current-voltage relation (see Fig. $5 C$ ), was $135 \pm 76 \mathrm{M} \Omega(n=26)$. The membrane time constant, measured by injecting small current steps and then fitting the voltage responses with a single exponential, was 1.9 $\pm 0.5 \mathrm{msec}(n=7)$. This corresponded well with the value of $2.0 \mathrm{msec}$ predicted from the product of the mean membrane capacitance and input resistance.

NM neurons exhibited strong outward rectification, as evidenced by the asymmetry in the responses to depolarizing and hyperpolarizing current steps (Fig. 1A). Negative current stcps caused the membrane potential to decay exponentially to a minimum and then sag to a less hyperpolarized level. The voltage responses to equivalent depolarizing current steps were substantially smaller: the membrane potential rose to a peak but decayed within $2-4 \mathrm{msec}$ to a lower level for the duration of the current step. These responses were unaffected when the sodium current was blocked with $1 \mu \mathrm{M}$ TTX. A plot of the steady state voltage versus current ( $V / I$ curve) shows that the start of the outward rectification, marked by a decrease in the slope resistance, was at $-67 \mathrm{mV}$ (Fig. 1B). 


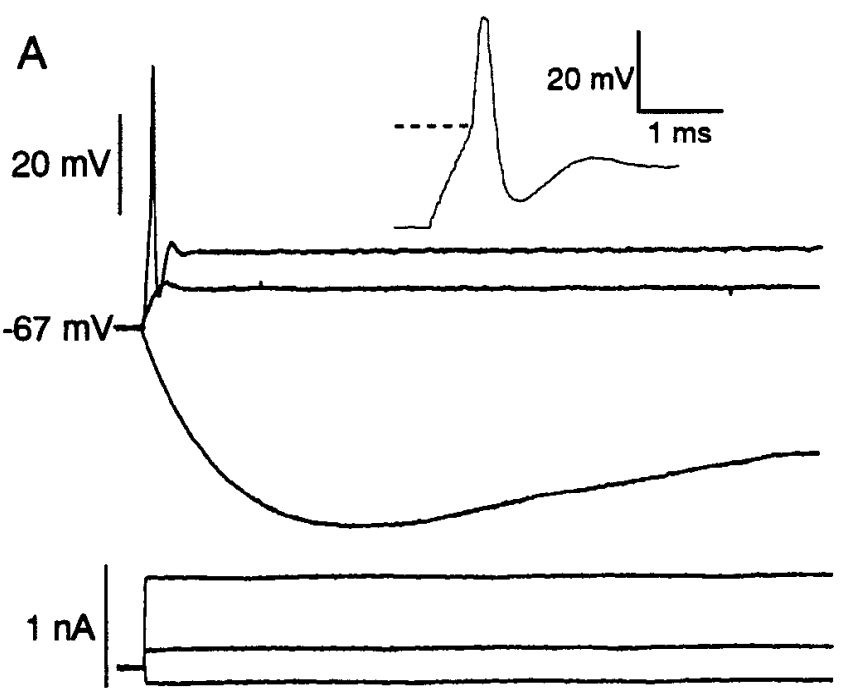

$10 \mathrm{~ms}$

C

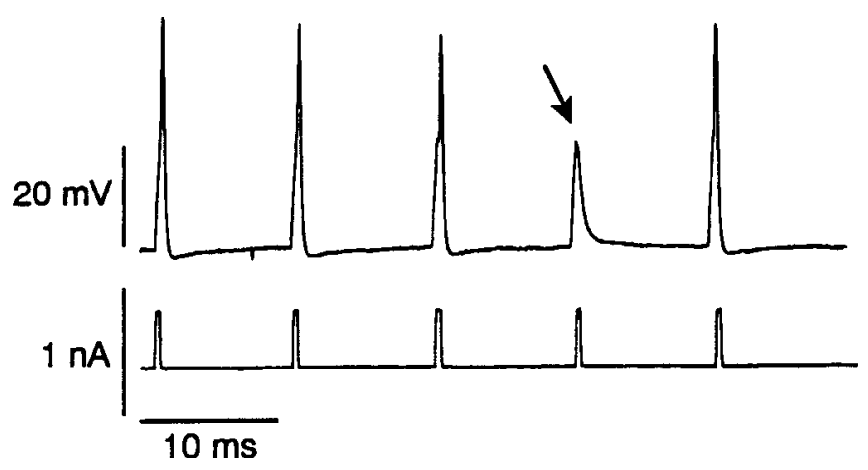

B
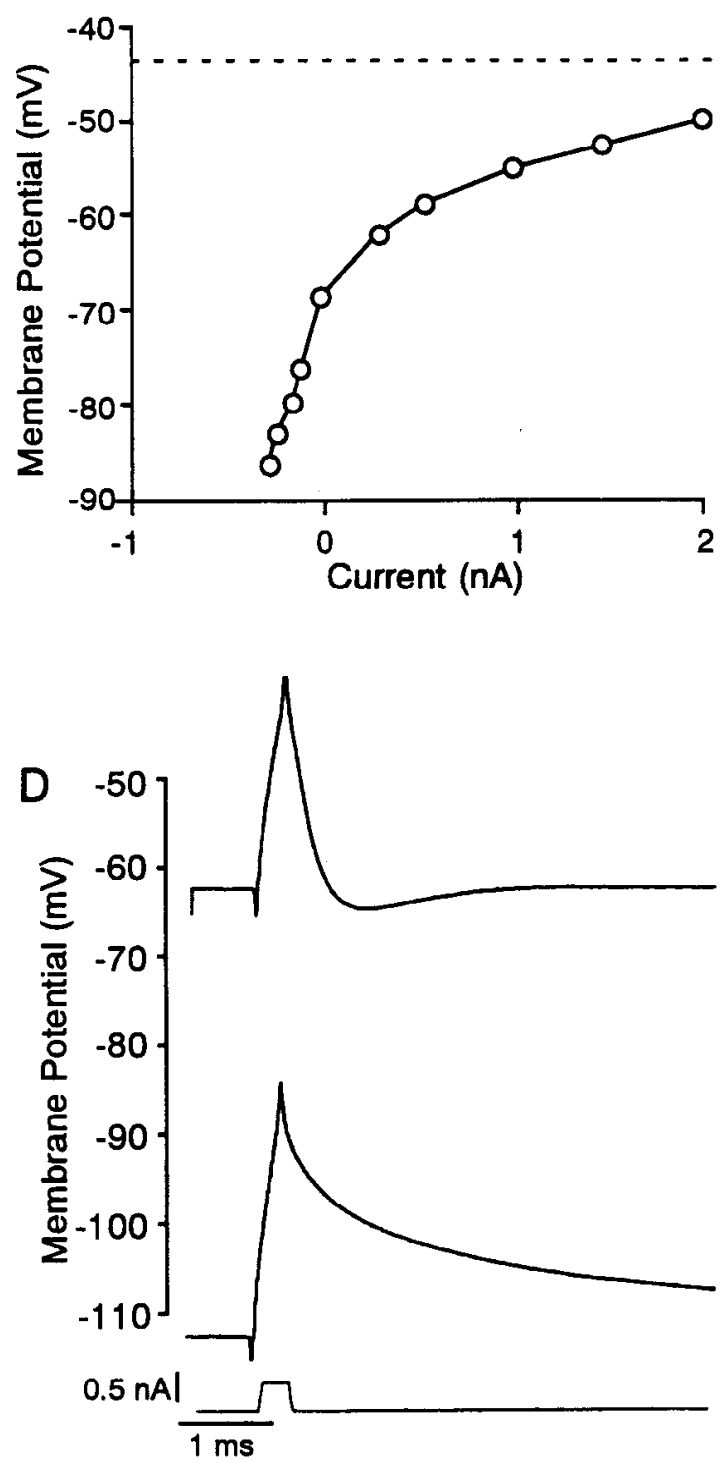

Figure 1. Subthreshold and suprathreshold responses of NM neurons. $A$, Superimposed traces of membrane potential responses (top) to depolarizing and hyperpolarizing current steps (bottom). Inset shows an expanded view of the action potential evoked with a suprathreshold current step. Dashed line marks firing threshold defined as the start of the fast rise in the voltage waveform. $B$, Plot of steady state membrane potential versus current. Measurements were taken $500 \mathrm{msec}$ after the current step onset. Dashed line marks firing threshold. $C$, Action potentials evoked during repetitive stimulation with a $0.4 \mathrm{msec}, 0.9 \mathrm{nA}$ current pulse. Arrow points to a subthreshold voltage response. $D$, Voltage responses to a brief current pulse applied at resting potential $(-62 \mathrm{mV})$ and during hyperpolarization to $-110 \mathrm{mV}$.

The voltage responses to brief current pulses repolarized rapidly in the presence of outward rectification. Figure $1 D$ shows the voltage deflection caused by a current pulse at two holding potentials. At resting potential $(-62 \mathrm{mV})$, the current pulse caused a $20 \mathrm{mV}$ deflection that extended into the shallow portion of the $V / I$ curve. After the peak, the membrane potential decayed rapidly to resting potential. The same pulse applied while the cell was hyperpolarized to $-110 \mathrm{mV}$, where the $V / I$ curve was steep, resulted in a voltage deflection that decayed at a substantially slower rate back to holding potential.

\section{Firing hehavior of NM neurons}

NM neurons fired a single action potential in response to a step of suprathreshold current (Fig. 1A). Firing threshold, defined as the level where the membrane potential begins its rapid rise toward the peak of the action potential (Fig. $1 A$, inset), was -40 $\pm 6 \mathrm{mV}(n=21)$ or approximately $22 \pm 5 \mathrm{mV}$ above resting potential. The amplitude of the action potential, measured from rest, was $44 \pm 5 \mathrm{mV}(n=21)$, and the duration, defined as the width at half the action potential height, was $0.25 \pm 0.06 \mathrm{msec}$ $(n=21)$. The action potential was followed by a brief afterhyperpolarization and overshoot, after which the membrane potential remained below firing level for the duration of the current step. Increasing the magnitude of the current steps did not evoke additional action polentials: the membrane potential following the action potential remained below threshold (dashed line in Fig. $1 B$ ) for the range of current steps examined.

To approximate synaptic potentials evoked by the firing of VIIIth fibers, brief current pulses were injected through the recording electrode. The pulse durations $(0.2-0.8 \mathrm{msec})$ were cho- 

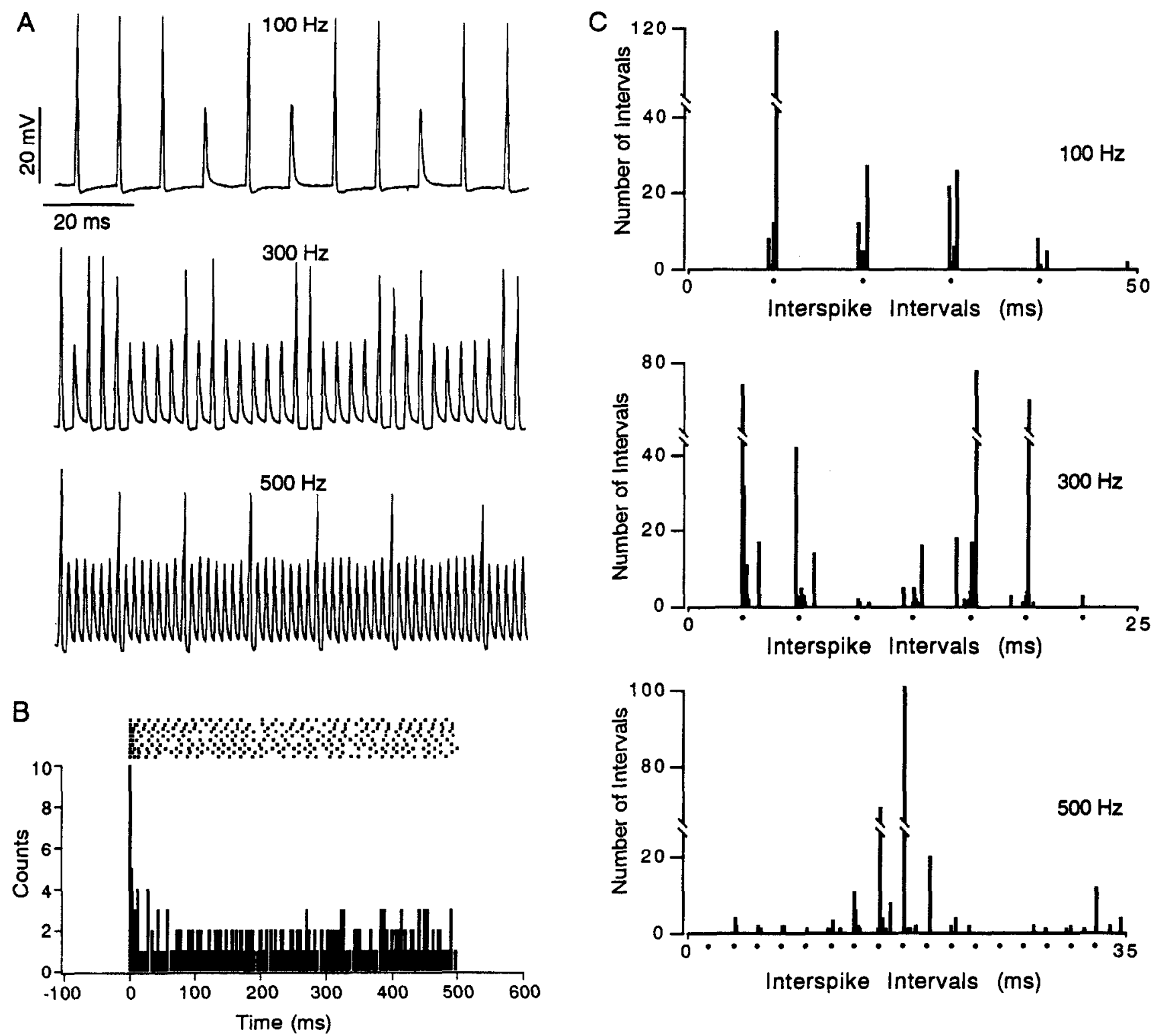

Figure 2. Effect of stimulus rate on the firing of NM neurons. $A$, Membrane potential responses to $0.4 \mathrm{msec}, 0.9 \mathrm{nA}$ current pulses (not shown) applied at 100,300, and $500 \mathrm{~Hz}$ for 500 msec. B. Peristimulus histogram (bottom) compiled from 10 stimulus trains (dot rasters, top) during 500 $\mathrm{Hz}$ stimulation. $C$, Histograms of interspike intervals, each compiled from 10 stimulus trains during stimulation at 100,300 , and $500 \mathrm{~Hz}$. Dots below abscissa mark integral multiples of the stimulus periods.

sen so that the pulses generated voltage deflections (arrow in Fig. $1 C$ ) that resembled stimulus-evoked synaptic potentials (Hackett et al., 1982; Jackson and Parks, 1982). Repetitive stimulation with the current pulses caused the neuron to fire repetitively (Fig. $1 C$ ). The action potentials were comparable to those evoked with the current steps but the afterhyperpolarizations were smaller and there were no overshoots. The subthreshold response (arrow in Fig. $1 C$ ) was brief and decayed at a rate comparable to that of the suprathreshold response.

The relation between NM firing and stimulus rate was examined by delivering the pulses at rates ranging from 100 to $1000 \mathrm{~Hz}$. The amplitudes of the current pulses were adjusted so that the pulses consistently evoked action potentials during low $(1-5 \mathrm{~Hz})$ rates of stimulation. Figure $2 A$ shows the typical firing behavior of an NM neuron during stimulation. Current pulses $(0.9 \mathrm{nA}, 0.4 \mathrm{msec})$ were delivered in stimulus trains last- ing $500 \mathrm{msec}$. At $100 \mathrm{~Hz}$, most of the pulses evoked action potentials. At 300 and $500 \mathrm{~Hz}$, the action potentials tended to occur at regular intervals, often in clusters of two to four sequential action potentials. The amplitude of the action potentials during the train was slightly smaller than that of the first action potential, but the duration and afterhyperpolarization remained relatively unchanged. Above $500 \mathrm{~Hz}$, only a single action potential was evoked at the start of the stimulus train (not shown). In general, NM neurons could not sustain discharge when the pulses were delivered at rates greater than $586 \pm 77$ $\mathrm{Hz}(n=14)$.

The discharge pattern of NM neurons during stimulation with the pulses was primary-like. Figure $2 B$ (bottom) shows a typical peristimulus histogram (PSTH) compiled from 10 stimulus trains (dot rasters shown above) during stimulation at $500 \mathrm{~Hz}$. As is the case with primary-like units (Pfeiffer, 1966), the PSTH 


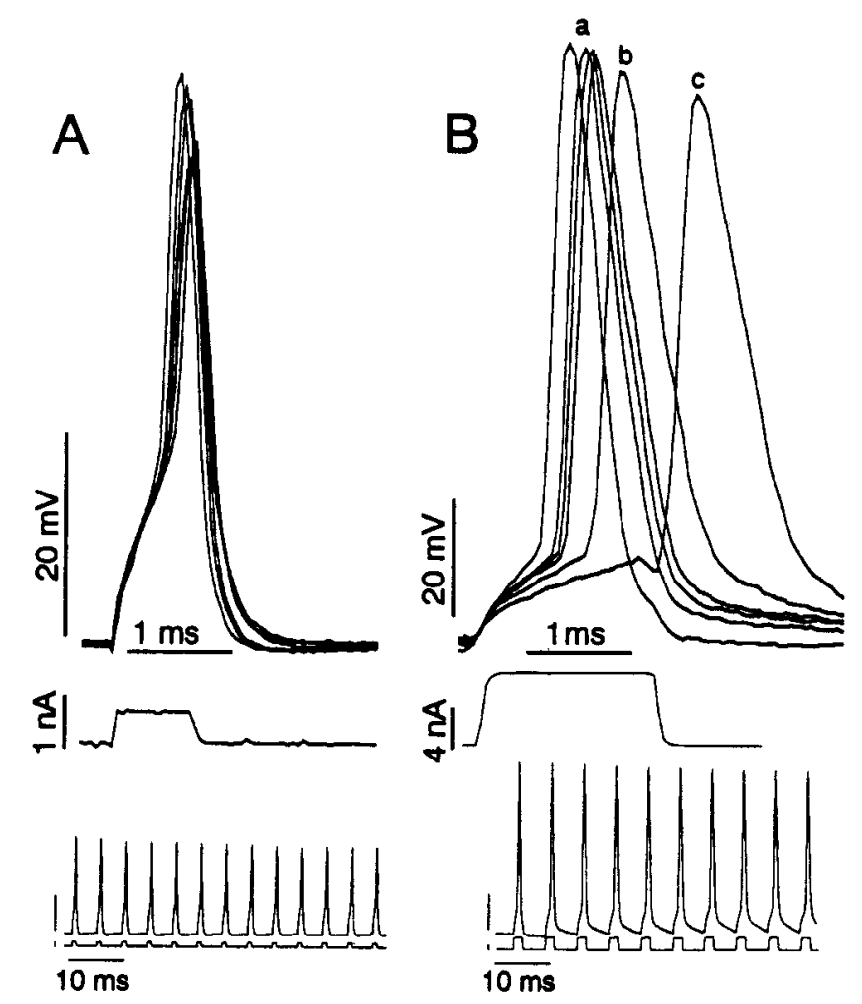

Figure 3. Comparison of phase-locking in NM neurons and cortical neurons. $A$, Superimposed records of the first four, the 20th, and the last action potentials evoked in an NM neuron when current pulses were delivered at $200 \mathrm{~Hz}$ for $800 \mathrm{msec}$. Resting potential was $-67 \mathrm{mV}$. $B$, Superimposed records of the first four $(a)$, the 17 th $(b)$, and the last $(c)$ action potentials evoked in a cat layer $\mathrm{V}$ pyramidal neuron during stimulation with a $167 \mathrm{~Hz}, 600 \mathrm{msec}$ pulse train. Resting potential was $-70 \mathrm{mV}$. Bottom traces in $A$ and $B$ show the voltage and current traces during the first $60 \mathrm{msec}$ of the stimulus train. Voltage and current calibration bars are numerically equal to those in upper traces.

showed a single peak at the start of the train, followed by a lower level of activity.

To examine phase-locking, interspike interval histograms were compiled from 10 stimulus trains during stimulation at 100 , 300, and $500 \mathrm{~Hz}$ (Fig. 2C). At each frequency, the histogram peaks occurred at a multiple of the stimulus period, indicating that the action potentials were phase-locked to the stimulus cycle. The vector strengths (Goldberg and Brown, 1969), which give the likelihood of an action potential occurring preferentially at a given phase of the stimulus cycle, were $0.99,0.96$, and 0.87 during stimulation at 100,300 , and $500 \mathrm{~Hz}$, respectively.

The ability to fire phase-locked action potentials to trains of current pulses does not appear to be a property of neurons in general. Figure $3 A$ shows superimposed records of the first four, the 20 th, and the last action potential evoked in an NM neuron during $800 \mathrm{msec}, 200 \mathrm{~Hz}$ stimulation with current pulses (stimulus train shown at bottom). The latencies of the action potentials increased slightly during the first four pulses but remained constant for the duration of the train. There was little jitter in the occurrences of the action potentials. Figure $3 B$ shows comparable records obtained with a layer $V$ pyramidal cell from the cat sensorimotor cortex during $600 \mathrm{msec}, 167 \mathrm{~Hz}$ stimulation. In contrast to NM neurons, pyramidal cells could not sustain phase-locking: the latencies of the evoked action potentials increased systcmatically throughout the train. Similar observations were made in neurons from the superficial layers of cortex.
To quantify the effectiveness of the current pulses in evoking action potentials at each stimulus frequency, the number of action potentials evoked during each stimulus train was divided by the number of current pulses. This measure gives the probability of each pulse evoking an action potential. Figure $4 \mathrm{~A}$ plots the firing probability against the stimulus frequency for a neuron that was probed with current pulses at three different amplitudes. Firing probability was greatest at low rates and decreased progressively with stimulus rate. Subthreshold stimuli did not evoke action potentials at any frequency (data not shown).

The pulse amplitude that was optimal for evoking action potentials depended on the stimulation frequency. At stimulus frequencies less than $300 \mathrm{~Hz}$, the firing probability increased with the pulse amplitude (Fig. 4A). This relation was nonmonotonic at higher frequencies: increasing the pulse amplitude from 2 to $2.5 \mathrm{nA}$ improved firing, but increasing the amplitude to 3 nA (solid triangles) decreased the firing probability. Figure $4 B$ shows that during $500 \mathrm{~Hz}$ stimulation, the $2 \mathrm{nA}$ pulse was ineffective at causing firing because the voltage deflections remained below threshold (inset). There were, however, occasional action potentials indicating that the sodium conductance underlying the action potential was not inactivated. Superposition of the action potentials evoked at the start and near the end of the train (inset) shows that their amplitudes and durations were comparable. In contrast, the $3 \mathrm{nA}$ pulse (Fig. $4 C$ ) was ineffective because it appeared to inactivate the action potential mechanism: the amplitudes of the action potentials systematically decreased with time during the train. Current pulses injected late in the train failed to evoke full action potentials, although the voltage deflections exceeded threshold of the initial action potential by $12 \mathrm{mV}$ (Fig. $4 C$, inset).

Because the firing probability decreased with increasing stimulus frequency, the average firing rate (= firing probability $x$ stimulus frequency) sustained during the train was a nonmonotonic function of stimulus frequency (data not shown). The peak of the relation was $233 \pm 128 \mathrm{~Hz}(n=14)$, which occurrcd during stimulation at $317 \pm 103 \mathrm{~Hz}$. However, this peak value may be an underestimate because the optimal pulse amplitude may not have been used in all cases. The highest sustained firing rate observed was $500 \mathrm{~Hz}$ during $500 \mathrm{~Hz}$ stimulation. Neurons were able to fire at higher rates only for brief periods of time at the start of the stimulus train. The highest instantaneous firing rate observed was $1 \mathrm{kHz}$ during $1 \mathrm{kHz}$ stimulation; however, only the first two pulses of the train evoked action potentials, with the second action potential being substantially smaller than the first.

\section{Characteristics of NM neurons under voltage clamp}

The characteristics of the ionic conductances underlying the subthreshold responses and the firing behavior of NM neurons were examined under voltage clamp. Figure $5 A$ shows the basic features of currents activated during $5 \mathrm{sec}$ voltage stcps from $-65 \mathrm{mV}$. The ACSF contained $1 \mu \mathrm{M}$ TTX to block sodium conductances. Depolarizing steps activated a fast activating, outward current that decayed slowly to a steady state level. The outward current deactivated rapidly: the current tails following the voltage steps were brief $(<3 \mathrm{msec})$ even at room temperature. Hyperpolarizing steps caused a small, persistent inward current whose amplitude increased with hyperpolarization.

Identification of the ionic basis of the outward current proved difficult because the reversal potential could not be measured reliably: the brief current tails were often obscured by capaci- 


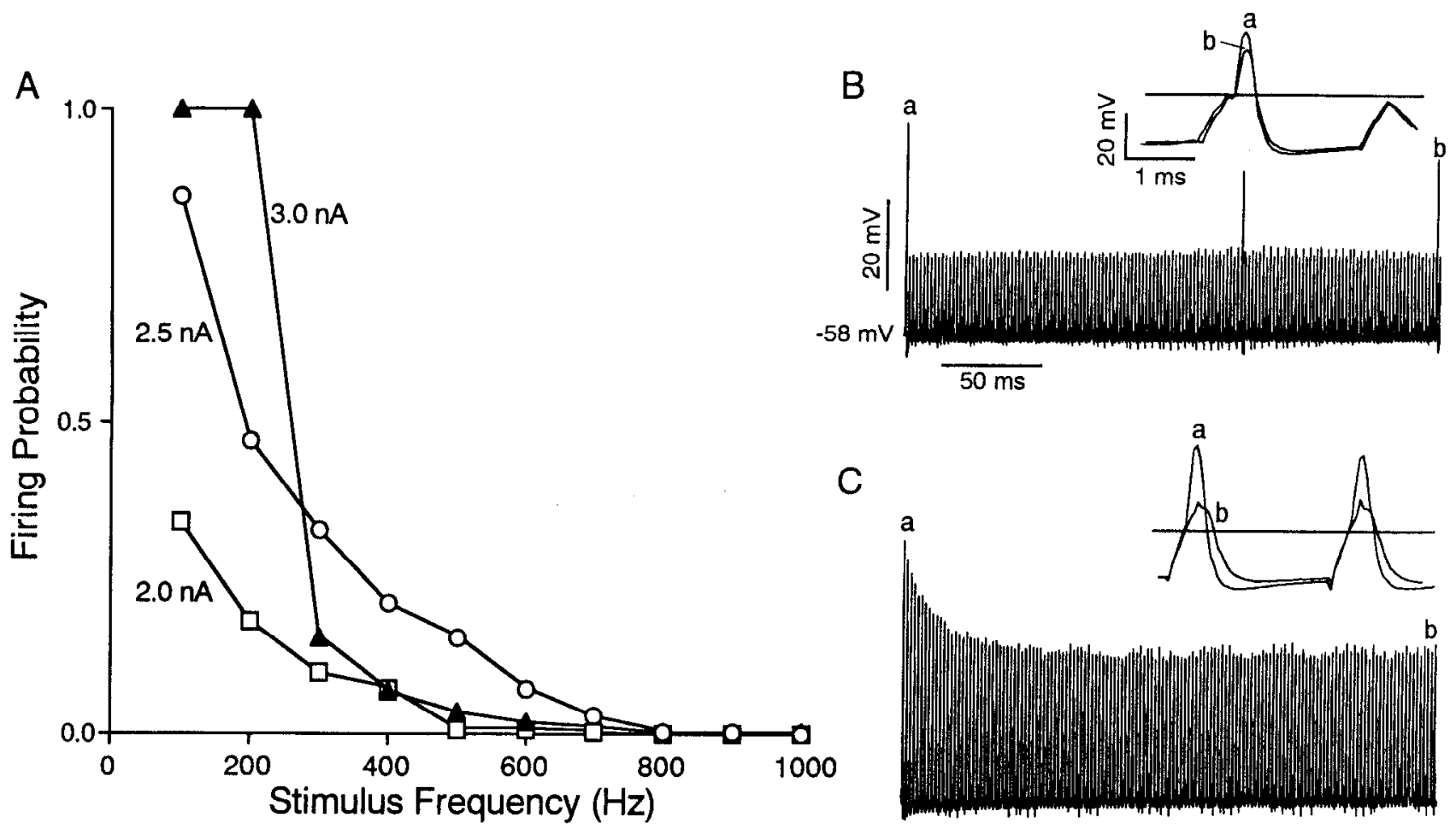

Figure 4. Effect of pulse amplitude on the firing of an NM neuron. $A$, Plots of the firing probability versus stimulus frequency for 0.4 msec current pulses with amplitudes of $2 \mathrm{nA}(\square), 2.5 \mathrm{nA}(O)$, and $3 \mathrm{nA} \mathrm{(A).B}$ and $C$, Voltage traces obtained during $500 \mathrm{~Hz}$ stimulation with $2.0 \mathrm{nA}(B)$ and $3.0 \mathrm{nA}(C)$ current pulses. Insets show superimposed traces of the voltage responses at the start $(a)$ and near the end $(b)$ of the stimulus train. Solid horizontal line in insets marks firing threshold of the first action potential.

tative artifacts. However, the outward current was carried primarily by potassium ions because raising the $\mathrm{K}^{+}$concentration of the ACSF from 3 to $9 \mathrm{~mm}$ caused a $24 \%(n=2)$ reduction in the outward current evoked during voltage steps to $-40 \mathrm{mV}$. In addition, the outward current was reduced by known potassium channel blockers (see below).

Both the peak and steady state components were voltage dependent. Figure $5 C$ plots the peak (solid circles) and steady state (open circles) current as a function of voltage ( $I / V$ curve). Activation threshold for both, taken as the voltage where the curves deviated from the linear, ohmic portion of the $I / V$ curve (dashed line), was $-65 \pm 3 \mathrm{mV}(n=20)$. Measurements at more positive potentials were difficult because the large currents often precluded reliable series resistance compensation or saturated the amplifiers.

The outward current had a rapid, sigmoidal rise (Fig. $5 A$, inset). The rate of activation increased with membrane potential, attaining $70 \%$ of its peak value at $0.94 \pm 0.30 \mathrm{msec}(n=$ 15) during steps to $-40 \mathrm{mV}$ and at $0.43 \pm 0.03 \mathrm{msec}(n=3)$ during steps to $-5 \mathrm{mV}$ (Fig. $5 D$ ).

After the peak, the current decayed to steady state values within $5 \mathrm{sec}$. The time course of inactivation was reasonably fit as a sum of two exponentials:

$$
I(t)=k_{0}+k_{1} * \exp \left(-t / \tau_{1}\right)+k_{2} * \exp \left(-t / \tau_{2}\right)
$$

The time constants, $\tau_{1}=1.2 \pm 0.3 \mathrm{sec}$ and $\tau_{2}=287 \pm 223$ $\mathrm{msec}(n=17)$, did not vary between $-50 \mathrm{mV}$ and $-10 \mathrm{mV}$. Figure $5 E$ plots the coefficients $k_{1}$ (solid circles) and $k_{2}$ (open circles) as a function of voltage. As with most neurons, the slow inactivating component $\left(k_{1}\right)$ was dominant al low vollages, whereas the faster inactivating component $\left(k_{2}\right)$ rose sharply at potentials above $-30 \mathrm{mV}$. The coefficient for the persistent component, $k_{0}$ (not shown), superimposed with the steady state $I / V$ curve in Figure $5 C$.

The voltage dependence of inactivation was determined using the paradigm shown in Figure $5 B$ (lower trace). The peak current that was activated by a voltage step to $-10 \mathrm{mV}$ was measured following a series of $5 \mathrm{sec}$ prepulses. Voltage steps were limited to potentials above $-75 \mathrm{mV}$ to ensure that the tails of the inward current, activated during hyperpolarizing steps (see Fig. $5 A, C$ ), did not contribute to the peak current. As the prepulse was made more positive, the magnitude of the peak current approached a nonzero, steady state level. The inactivation parameter at each potential was calculated by normalizing (dividing) the peak current following the prepulses by the maximum peak value. Figure $5 C$ (solid triangles) plots inactivation as a function of prepulse voltage. The inactivation curve was fitted with a Boltzmann equation (smooth curve in Fig. $5 C$ ) of the form

$$
\begin{aligned}
\text { inactivation }(V)= & \left(1-I_{\min } / I_{\max }\right) /(1+\exp ([V-E] / k)) \\
& +I_{\min } / I_{\max },
\end{aligned}
$$

where $E=-54 \pm 4 \mathrm{mV}, k=6.5 \pm 2.1(n=8)$, and $I_{\max }$ and $I_{\min }$ are, respectively, the maximum and minimum values of the peak current.

\section{Pharmacological characterization of the outward current}

The outward current was reduced by 4-aminopyridine (4-AP). In Figure $6, A$ and $B$ show the current traces obtained with voltage steps from $-70 \mathrm{mV}$ both before and during application of $200 \mu \mathrm{m}$ 4-AP. At this concentration, the outward current evoked by voltage steps to $-45 \mathrm{mV}$ was reduced by $84 \pm 13 \%$ 

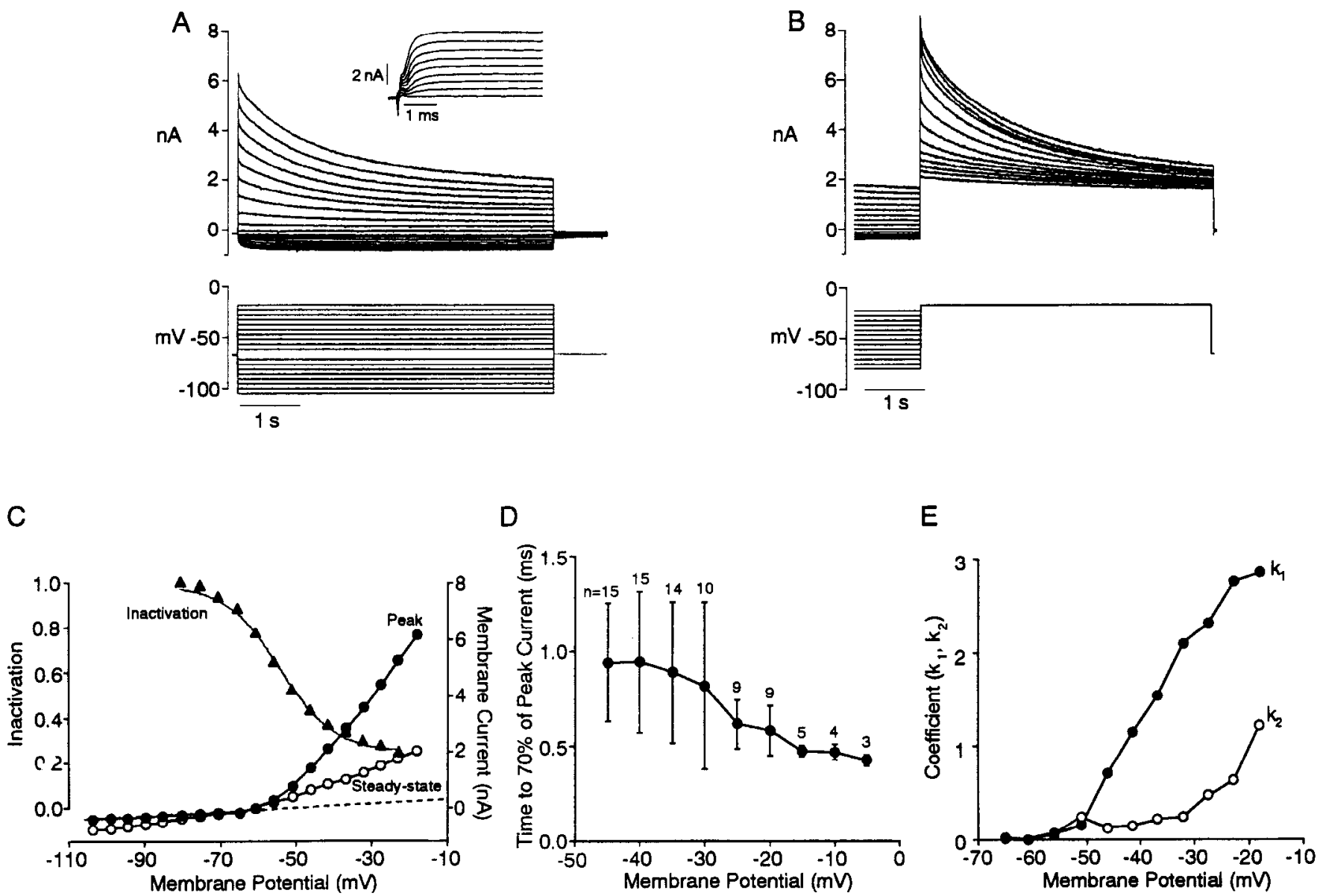

Figure 5. Properties of the outward current. $A$, Superimposed traces of membrane current (top) evoked during $5 \mathrm{mV}$ incremental voltage steps (bottom) from a holding potential of $-65 \mathrm{mV}$. Inset shows current traces at expanded time scale. B, Superimposed traces of membrane current (top) evoked during voltage steps to $-20 \mathrm{mV}$ following a series of $5 \mathrm{sec}$ prepulses (bottom). $C$, Plot of membrane current measured 4 msec after the onset of the voltage step in $A(\bullet)$. At potentials above activation threshold $(-60 \mathrm{mV})$ for the outward current, measured values correspond to the peaks of the membrane current. Below activation threshold, measured values are equivalent to the leak current. Dashed line gives the linear regression for the ohmic portion of the current-voltage curve. $O$, the steady state membrane current measured near the end of the 5 sec voltage step in $A$. $\Delta$, the normalized inactivation curve for the data in $B$. $D$, Plot of mean $( \pm \mathrm{SD})$ time required for the outward current to reach $70 \%$ of its peak value verses membrane potential. $E$, Plot of coefficients (see Eq. 1) for slow $\left(k_{1}, \sigma\right)$ and fast $\left(k_{2}, O\right)$ inactivating components of the outward current.

$(n=10)$. The reduction was reversible after approximately 5 min of wash. The residual current (Fig. $6 B$ ) was relatively persistent, decreasing only slightly during $5 \mathrm{sec}$ voltage steps, and did not change when the prepulses preceded the voltage steps (data not shown). A plot of the peak current against voltage (Fig. 6D, open circles) shows that the unblocked component activated near the activation threshold of the control current $(-65 \mathrm{mV})$. The 4-AP-sensitive component, obtained by digitally subtracting the residual current from the control traces, decayed to a nonzero steady state level that increased with voltage (Fig. 6C).

4-AP does not appear to block selectively the transient component of the outward current. Increasing the concentration of 4-AP from 200 to $500 \mu \mathrm{M}$ caused a further reduction in the residual current, suggesting that the persistent component is also, albeit less, sensitive to 4-AP ( $n=4$, data not shown). In one cell, application of $2 \mathrm{mM} 4$-AP produced a complete block of the outward current. Application of $20 \mu_{\mathrm{M}}$ 4-AP did not completely block the transient component but caused a $49 \pm$ $8 \%(n=2)$ reduction in the peak current evoked during voltage steps to $-25 \mathrm{mV}$.
The 4-AP-sensitive component activated at a rate that was comparable to the control current (Fig. $6 C$, inset), with the current reaching $70 \%$ of the peak value at $1.2 \pm 0.4 \mathrm{msec}(n=$ 10) during voltage steps to $-45 \mathrm{mV}$. The residual current also activated rapidly but its time course could not be reliably measured because the residual current was relatively small and the capacitative artifacts often obscured its rise. One notable feature of the residual current was that there was often a slowly rising component that was most prominent in neurons in slices taken from caudal NM. The time required for the current to reach its peak value ranged from 8 to $242 \mathrm{msec}$ (mean $\pm \mathrm{SD}=94 \pm$ $110 \mathrm{msec} ; n=10$ ) for neurons recorded along the rostral-caudal axis of NM.

Application of $10 \mathrm{~mm}$ tetraethylammonium chloride (TEA) reversibly reduced the current by $29 \pm 6 \%(n=3$; Fig. $7 A)$ during voltage steps to $-45 \mathrm{mV}$, but did not appear to block preferentially either the transient or persistent component: the time course of the TEA-sensitive component (Fig. $7 C$ ) was similar to that of the control traces (Fig. 7A). There was no obvious change either in the time constants of inactivation or in their 

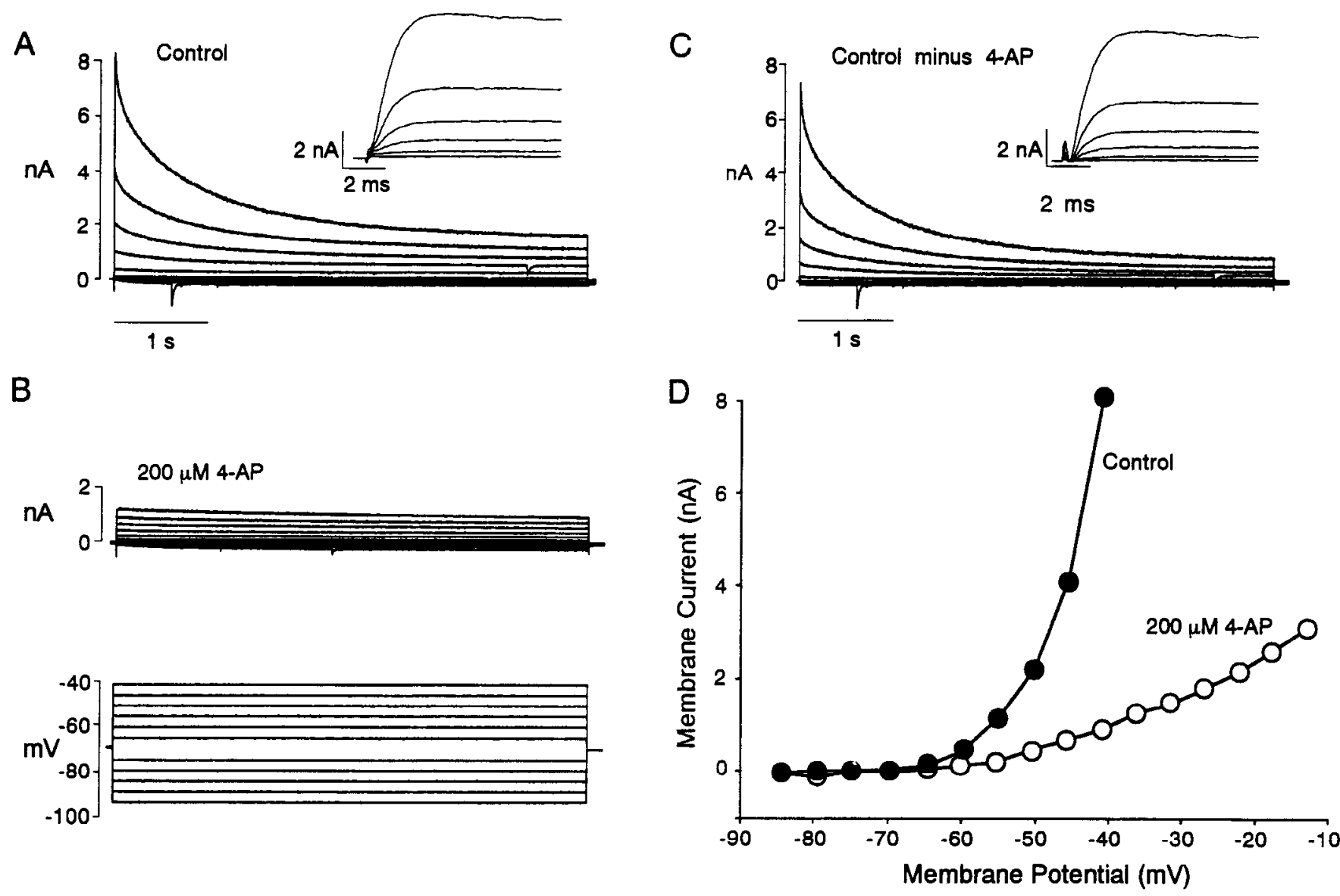

Figure 6. Effect of 4-aminopyridine on the outward current. $A$ and $B$, Membrane currents evoked in voltage clamp from a holding potential of $-70 \mathrm{mV}$ before $(A)$ and during $(B)$ application of $200 \mu \mathrm{M}$ 4-AP. $C, 4-\mathrm{AP}$-sensitive current obtained by digitally subtracting the current traces in $B$ from those in $A$. Insets in $A$ and $C$ show onset of the control and 4-AP-sensitive currents at expanded time scalcs. $D$, Current-voltage relation obtained before $(\Theta)$ and during application of 4-AP $(0)$.

relative proportions (coefficients in Eq. 1). Plot of the peak current versus voltage (Fig. $7 D$ ) shows that TEA first produced a block near the activation threshold of the outward current $(-55 \mathrm{mV})$.

Several experiments designed to isolate possible calcium-dependent potassium currents were performed. Changing the external solution from normal ACSF to a nominally calcium-free ACSF containing $0.5 \mathrm{~mm}$ EGTA and $5 \mathrm{~mm} \mathrm{MgCl}_{2}$ did not reduce the outward current $(n=3)$. Blockade of calcium channels by substituting $\mathrm{MnCl}_{2}$ for $\mathrm{CaCl}_{2}$ in the ACSF caused a $29 \pm 11 \%$ $(n=3)$ reduction in the outward current evoked by voltage steps to $-45 \mathrm{mV}$. However, the manipulation was not selective for calcium-dependent potassium currents: the reduction still occurred when the slices were initially perfused with the nominally calcium-free solution and the recordings performed with $10 \mathrm{mM}$ EGTA or BAPTA in the pipette solution to chelate internal calcium $(n=3)$. Charybdotoxin (CTX), a known blocker for the BK calcium-dependent potassium channels (Miller et al., 1985), was also nonselective: application of $30 \mathrm{nM}$ CTX caused a $40 \%$ reduction in the outward current $(n=2)$ evoked by voltage steps to -30 and $-45 \mathrm{mV}$ that still occurred when the experiments were performed with $10 \mathrm{~mm}$ BAPTA in the electrode solution and with $\mathrm{MnCl}_{2}$ substituted for $\mathrm{CaCl}_{2}$ in the bath ACSF $(n=2)$. Finally, application of $200 \mathrm{~nm}$ apamin, a known blocker for the SK calcium-dependent potassium channcls (Hugues et al., 1982), had no effect on the outward current $(n=2)$. Thus, under our recording conditions, NM neurons do not appear to have any appreciable calcium-dependent potassium currents.

\section{Effect of 4-AP on subthreshold responses and firing}

The role of the outward current in shaping the subthreshold responses and discharge properties of NM neurons was assessed by examining the changes caused by application of 4-AP. Figure $8 A$ shows the voltage responses to current steps before and during application of $200 \mu \mathrm{M} 4-\mathrm{AP}$. In the presence of 4-AP, the voltage responses to both depolarizing and hyperpolarizing current steps increased. However, the outward rectification was not completely eliminated: the voltage response in the hyperpolarizing direction remained larger than in the depolarizing direction. The increase in the hyperpolarizing direction indicates that, for this cell, the 4-AP-sensitive component of the outward current was partially activated at resting potential $(-58 \mathrm{mV})$. At the end of the current step, the membrane potential repolarized at a slower rate in the presence of 4-AP.

The effects of 4-AP on the suprathreshold responses are shown in Figure $8, B$ and $C$. In the presence of $200 \mu \mathrm{M} 4-\mathrm{AP}$, suprathreshold current steps evoked a single action potential after which the membrane potential remained above threshold (Fig. $8 B$ ). Repetitive firing was never observed in the presence of 4-AP. Figure $8 C$ shows the action potentials evoked with a current pulsc. In the presence of 4-AP, the action potential amplitude increased by $35 \pm 18 \%(n=7)$ and the duration 

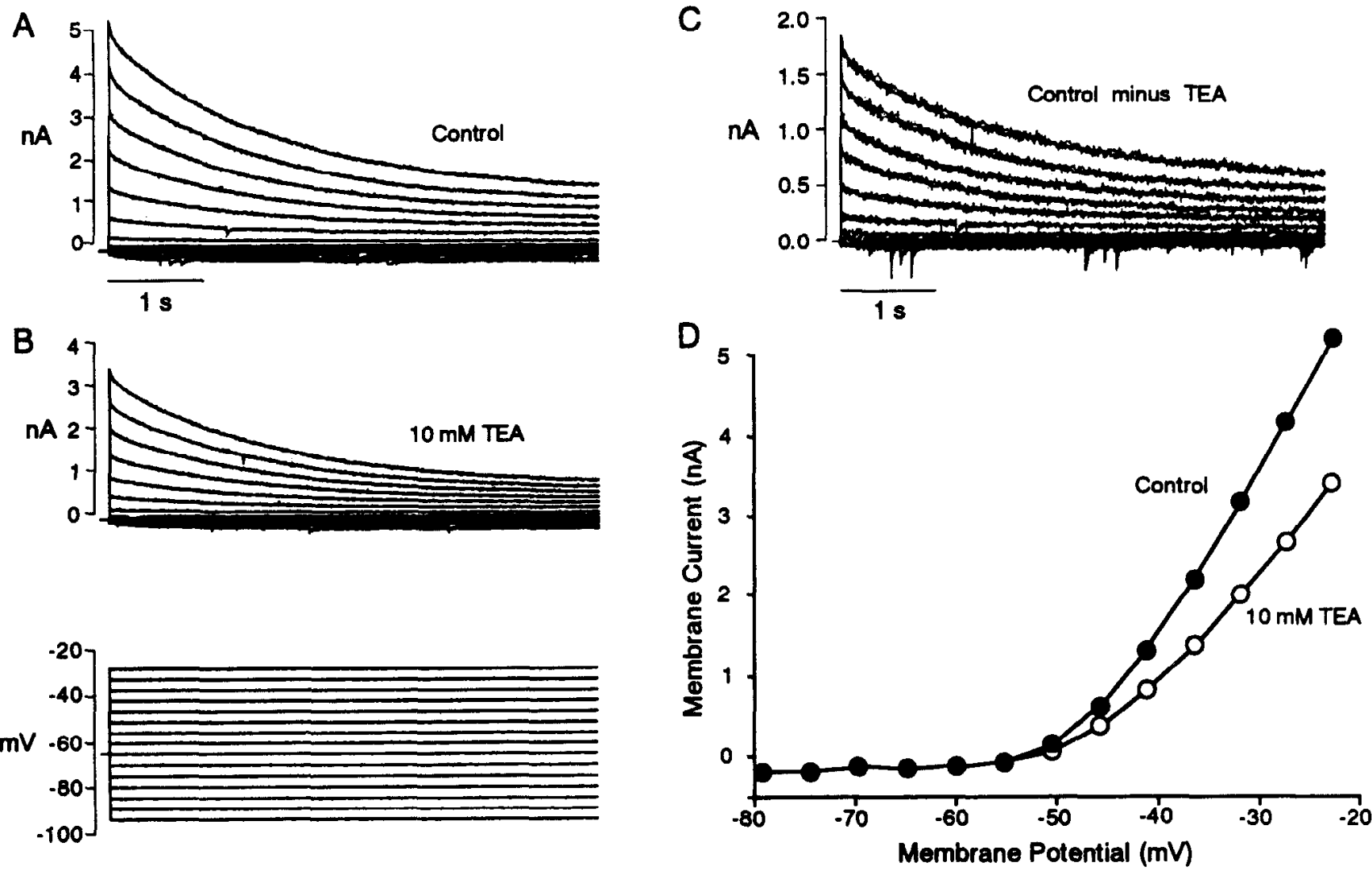

Figure 7. Effect of tetraethylammonium chloride on the outward current. $A$ and $B$, Membrane currents evoked in voltage clamp from a holding potential of $-65 \mathrm{mV}$ before $(A)$ and during $(B)$ application of $10 \mathrm{~mm}$ TEA. $C$, TEA-sensitive current obtained by digitally subtracting the current traces in $B$ from those in $A . D$, Current-voltage relation obtained before $(\bullet)$ and during application of $10 \mathrm{mM}$ TEA (O).

increased by $116 \pm 40 \%(n=7)$. After the action potential, the membrane potential decayed slowly to resting potential with no afterhyperpolarization.

The effect of 4-AP on the firing of NM neurons during stimulation with trains of pulses depended on the stimulus rate. Figure $9 A$ plots the relation between firing probability and stimulus rate both before (solid circles) and during application of 4-AP (open circles). In general, 4-AP caused an increase in the firing probability during low-frequency stimulation and a decrease in firing probability during high-frequency stimulation. Figure $9 B$ shows the voltage records obtained during stimulation at 300,500 , and $600 \mathrm{~Hz}$ before and during application of 4-AP. During $300 \mathrm{~Hz}$ stimulation, 4-AP caused previously subthreshold responses to cross firing level. During $500 \mathrm{~Hz}$ stimulation, the amplitudes of the action potentials in the presence of 4-AP were variable and were substantially smaller than the first action potential of the train, suggesting partial inactivation of the sodium conductance underlying the action potentials. At $600 \mathrm{~Hz}$, the pulses in the presence of 4-AP failed to evoke action potentials throughout the train. Several lines of evidence suggest that the sodium conductance inactivated: (1) the amplitude of the action potential rapidly decreased during the train (Fig. $9 B$, inset), (2) current pulses failed to evoke action potentials though the voltage deflections exceeded threshold (inset, horizontal line), and (3) in other cells, increasing the amplitude of the current pulses did not evoke additional action potentials.

Application of 4-AP increased the temporal summation during the train. In normal ACSF (Fig. 9B, left), the voltage re- sponses to the current pulses repolarized to a level near resting potential (dottcd lines) during the train. Application of $4-\Lambda \mathrm{P}$ caused the responses to repolarize at substantially more depolarized levels (Fig. $9 B$, right). This increase in the average membrane potential probably contributed to the inactivation of the action potential mechanism.

\section{Discussion}

This study examined the electrophysiological properties that underlie the firing of neurons in the chick NM. NM neurons fired best to rapidly changing stimuli: they fired only a single action potential in response to current steps but fired repetitively to trains of brief current pulses. Both the action potentials and the subthreshold responses to the current pulses repolarized rapidly. NM neurons could fire action potentials when the current pulses were delivered at rates as high as $\sim 600 \mathrm{~Hz}$. Voltageclamp studies revealed that a rapidly activating, slowly inactivating outward current underlies these response properties. Reduction of this current with 4-AP increased the amplitude and duration of the action potentials and reduced the ability of $\mathrm{NM}$ neurons to fire during high rates of stimulation.

The electrophysiological properties of NM neurons are very similar to those of bushy cells in the mammalian AVCN (Oertel, 1983; Wu and Oertel, 1984; Manis and Marx, 1991). The input resistance and membrane time constants were comparable to those of type II, presumably bushy, cells of the guinea pig ventral cochlear nucleus (Manis and Marx, 1991). NM neurons, like bushy cells, exhibited strong outward rectification near resting 

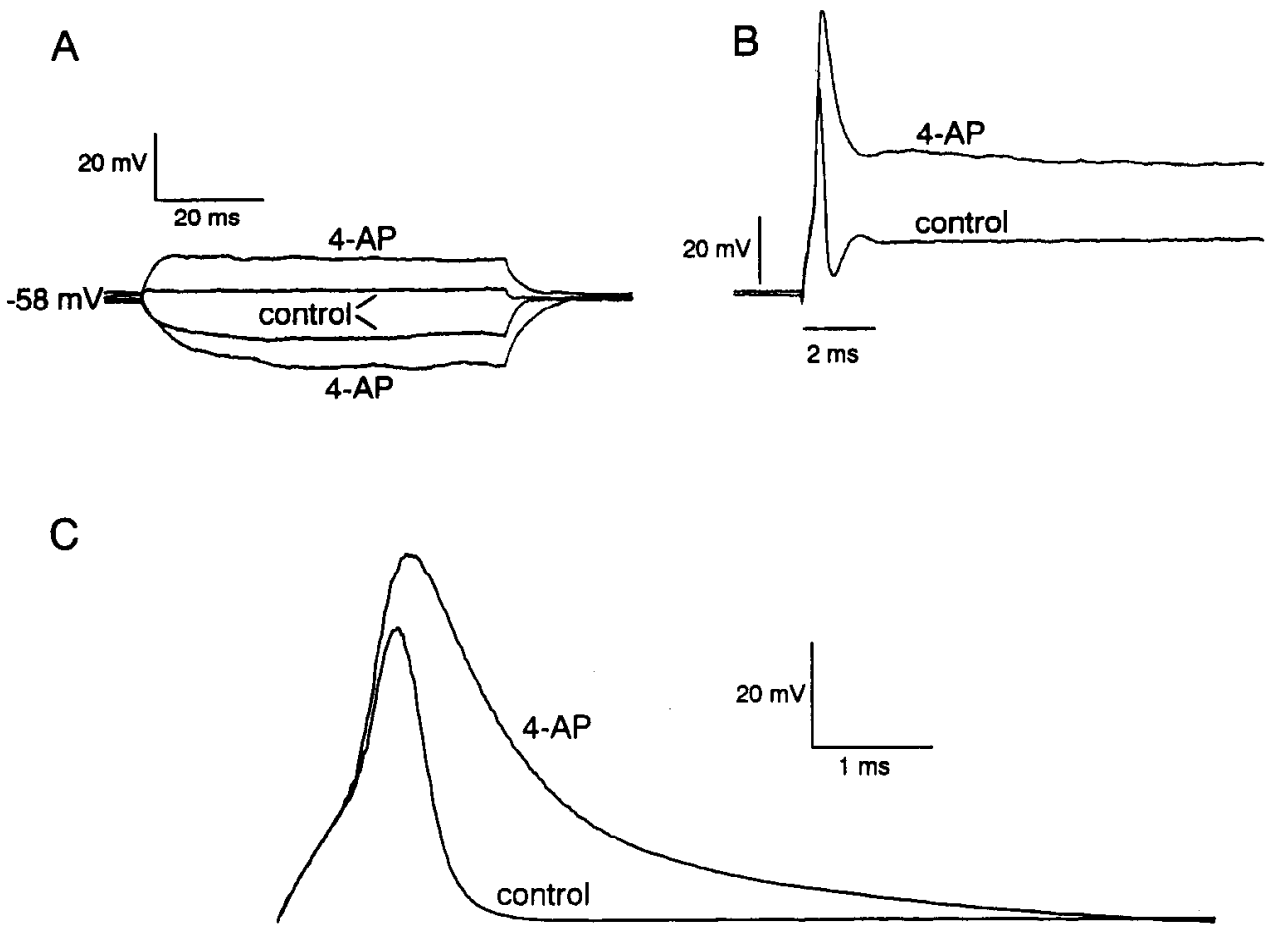

Figure 8. Effects of 4-aminopyridine on the subthreshold and suprathreshold responses. $A$, Superimposed traces of membrane potential responses (top) to depolarizing and hyperpolarizing $0.1 \mathrm{nA}$ current steps (not shown) before and during application of $200 \mu \mathrm{M}$ 4-AP. $B$, Superimposed traces of membrane potential responses to suprathreshold, 1.7 nA current steps before and during application of $200 \mu \mathrm{M}$ 4-AP. C, Superimposed action potentials evoked with a brief current pulse before and during application of $200 \mu \mathrm{M}$ 4-AP. potential and did not fire repetitively with steadily applied current. This supports morphological studies suggesting that NM neurons are the mammalian homolog of bushy cells (Boord and Rassmusen, 1966; Rubel and Parks, 1975; Jhaveri and Morest, 1982).

\section{Firing of NM neurons in response to current pulses}

Brief current pulses were injected through the recording electrode to produce voltage deflections that resembled stimulusevoked synaptic potentials (Hackett et al., 1982; Jackson and Parks, 1982). The rates that the pulses were delivered (100$1000 \mathrm{~Hz})$ are probably comparable to the rates $(100-1200 \mathrm{~Hz}$ ) that the synaptic potentials would arrive in NM neurons during acoustic stimulation. Current pulses have been shown to reproduce successfully the change in firing rate caused by synaptic potentials in neocortical neurons (Reyes and Fetz, 1993a,b). The use of current pulses instead of stimulus-evoked synaptic potentials allowed us to study exclusively postsynaptic mechanisms underlying the firing behavior, thereby ruling out presynaptic factors. Synaptic potentials evoked by stimulation of the VIIIth nerve in vitro, for example, can be quite variable in amplitude (Trussell et al., 1993) and can be contaminated by inhibitory potentials (Oertel, 1983; Wu and Oertel, 1984).

The current pulses successfully reproduced several firing properties of NM neurons recorded in vivo during acoustic stimulation (Sachs and Sinnott, 1978; Sullivan and Konishi, 1984; Warchol and Dallos, 1990). The interval histograms and vector analyses indicate that the action potentials evoked by the current pulses were phase-locked to the stimulus cycle. Moreover, the discharge pattern was primary-like (Pfeiffer, 1966). The first pulse of the train always evoked an action potential, while subsequent pulses had a lower probability of evoking action potentials (Fig. $2 B$ ). Though the action potentials tended to occur in clusters, the clusters occurred randomly throughout the train so that, from trial to trial, each pulse had an equal probability of evoking action potentials. Thus, the PSTHs had a peak at the start of the train followed by a lower, steady level of action potential activity. Unlike the PSTHs obtained with "chopper"like units (Pfeiffer, 1966), there were no additional peaks.

Because the amplitudes of the current pulses were constant, the firing produced by the stimulus paradigm may underestimate the firing evoked during acoustic stimulation. At stimulus rates greater than $200 \mathrm{~Hz}$, most of the voltage responses to the current pulses did not exceed threshold (Figs. $2 A, 4 B, 9 B$ ). Variability in the membrane potential could conceivably lead to additional threshold crossings. For example, the occasional action potentials in the neuron of Figure $4 B$ may have been triggered by small fluctuations in the membrane potential that caused some of the voltage deflections to cross threshold. Unlike stimulation with constant current pulses, the amplitude of the synaptic potentials will vary during acoustic stimulation, depending on how many impulses from the two or three VIIIth nerve fibers arrive synchronously. Moreover, the amplitude of the stimulusevoked synaptic currents in NM vary substantially with stimulus frequency (Trussell et al., 1993); consequently, irregularities in the instantaneous firing rate of VIIIth nerve afferents during acoustic stimulation (Rose et al., 1967) will result in synaptic potentials with highly variable amplitudes. A more complex stimulus paradigm that reflects the irregularity in the VIIIth nerve firing and incorporates frequency-dependent changes in the amplitude of the synaptic potentials may give a better approximation of the ncurons' discharge properties.

\section{Characteristics of the outward current}

The distinguishing characteristics of the outward current in NM are its activation threshold near resting potential, rapid activation, and slow inactivation. The current is composed of an inactivating and a persistent component. We could not definitively conclude from our whole-cell recordings whether the two components are due to a single conductance that does not inactivate completely or whether they are due to two or more conductances with different kinetics and voltage dependence. 

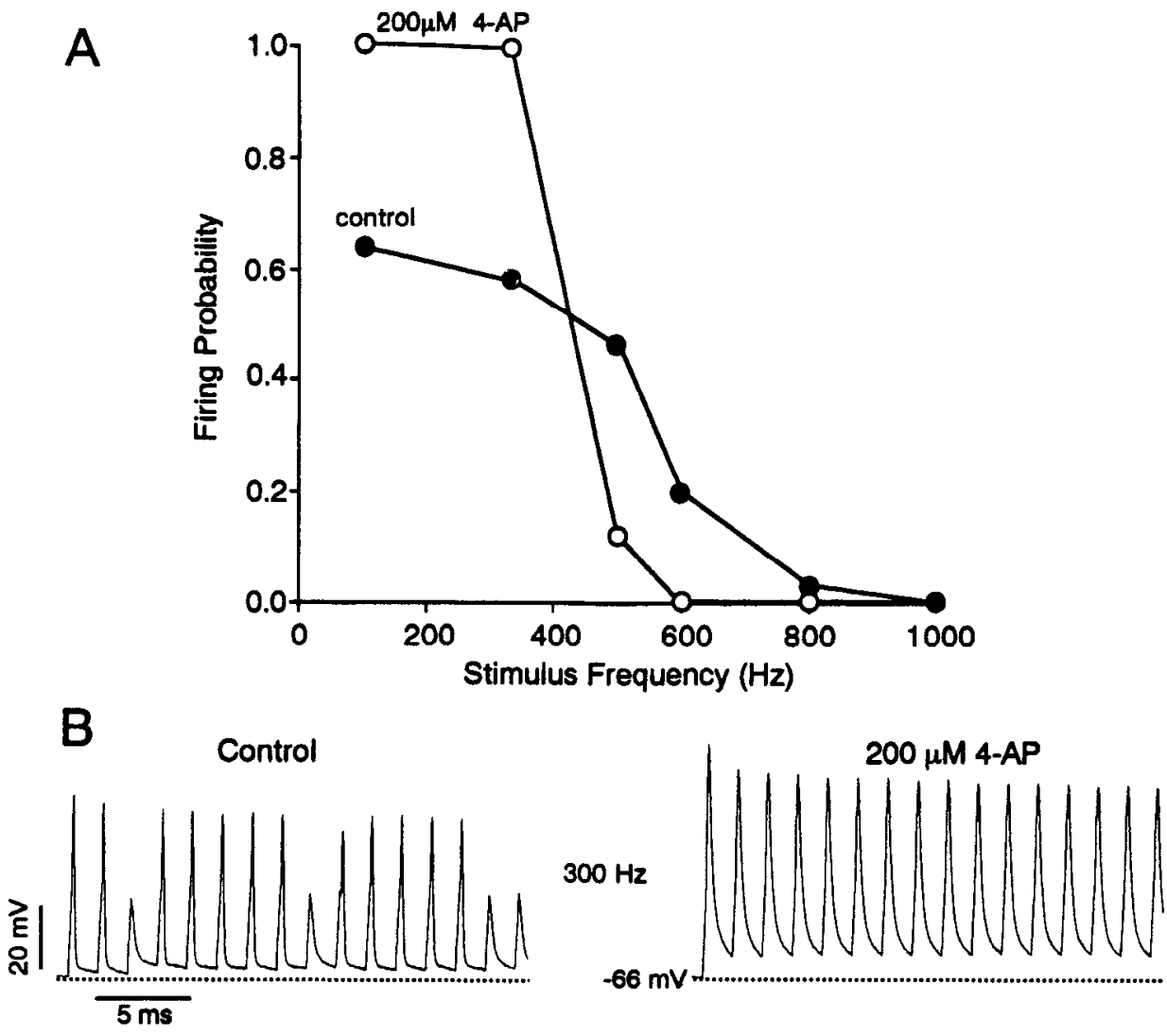

Figure 9. Effects of 4-aminopyridine on the firing. $A$, Plots of firing probability versus stimulus frequency obtained before $(O)$ and during $(O)$ application of $200 \mu \mathrm{M}$ 4-AP. B. Membrane potential responses during stimulation at 300,500 , and $600 \mathrm{~Hz}$ before (left) and during (right) application of 4-AP. Dotted horizontal lines mark resting potential. Inset shows selected voltage responses during $600 \mathrm{~Hz}$ stimulation at expanded time scale. Solid horizontal line in inset marks firing threshold.
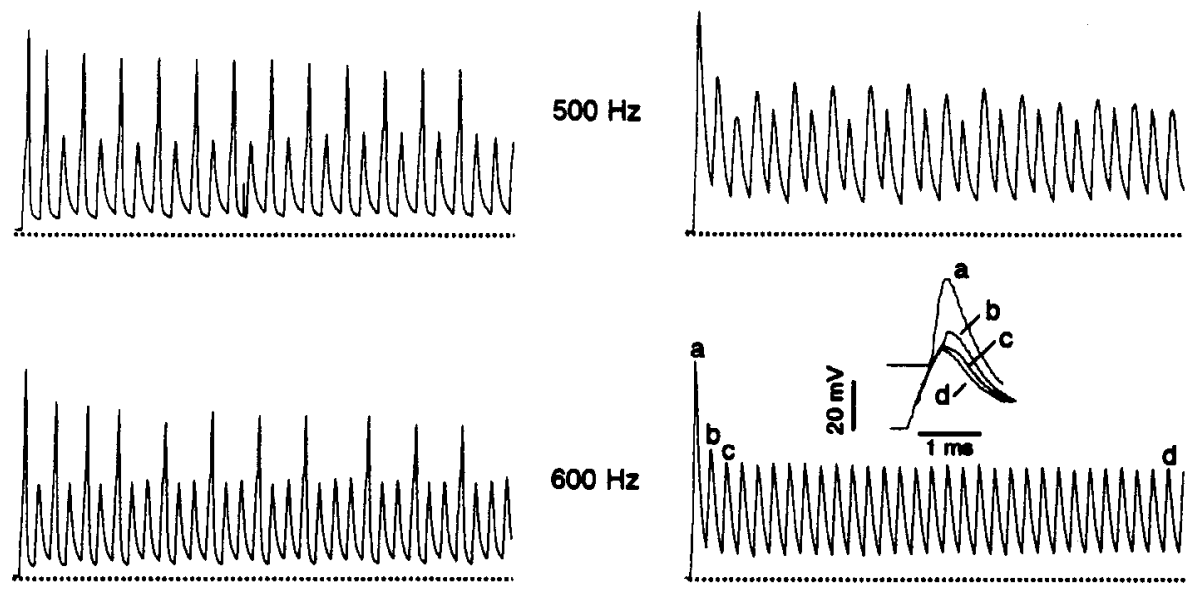

Neither TEA or 4-AP appeared to block either of the components selectively, although 4-AP reduced the inactivating component to a greater extent than the persistent component.

The properties of the outward currents in NM differ from those described in the type II neurons of the mammalian VCN (Manis and Marx, 1991). The primary difference was that in the type II cells, the outward currents were persistent. However, the $100 \mathrm{msec}$ voltage steps used by Manis and Marx (1991) may have been too brief to observe slow inactivation, particularly at room temperature where the kinetics would be slower. NM and type II neurons also differed in their sensitivity to pharmacological blockers. The outward current in NM neurons were more sensitive to 4-AP: $200 \mu_{\mathrm{M}}$ 4-AP reduced the outward current by the same amount as $4 \mathrm{~mm} 4$-AP did in type II neurons. In both cases, however, the 4-AP-sensitive component had a threshold near resting potential. Unlike type II neurons, TEA did not specifically block a high-threshold component in NM neurons.

The characteristics of the outward current can account for many of the firing properties of NM neurons. Because the outward current activated rapidly near resting potential, NM neurons fired only a single action potential during steadily applied current. During a current step, the membrane potential crossed threshold only at the start of the step while the outward current was rapidly approaching steady state activation. Because the outward current was relatively persistent, the membrane potential remained below threshold for the duration of the step. Current pulses applied at low rates were effective at evoking action potentials probably because the relatively long interstimulus interval allowed the outward current to deactivate between the 
pulses. Pulses delivered at higher rates were less effective at evoking action potentials probably because the rapid arrival of voltage deflections caused sufficient sustained depolarization to partially activate the outward current and prevent many of the voltage deflections from crossing threshold. At very high rates of stimulation, the intervals between the rectangular pulses were sufficiently short for the stimulus train to approximate a long current step. In such cases, the outward current, after a short delay, attenuated the voltage deflections below firing threshold for the duration of the train. As was the case with current steps, only a single action potential was evoked at the start of the train. Another possibility, particularly for large pulses, was that at high rates, sufficient depolarization developed during the train to inactivate the action potential mechanism.

When the outward current was reduced with $200 \mu \mathrm{M} 4-\mathrm{AP}$, the amplitude of the voltage responses to current steps increased and the decay rate decreased. These effects can account for the changes in the responses of NM neurons to current pulses in the presence of 4-AP. Application of 4-AP increased the firing probability during low stimulation rates probably because the increase in the amplitude of the voltage deflections allowed more threshold crossings to occur. During high rates of stimulation, application of 4-AP decreased the firing probability because the increase in the amplitude and the decrease in the decay rate of the voltage deflections caused temporal summation to increase during the stimulus train. The resulting sustained depolarization inactivated the action potential mechanism.

\section{Functional role of the outward current}

The outward current is necessary for NM neurons to relay temporal information reliably to NL. In effect, the outward current imparts high-pass filtering characteristics to NM neurons: its rapid activation and slow inactivation allow rapidly changing potentials to cross threshold but attenuates slowly changing potentials that contain no temporal information and can instead lead to cessation of firing. The ability to maintain firing for the duration of the acoustic stimulus ensures that acoustic information is effectively relayed throughout the sound localization pathway. For example, because the firing of NL neurons depends on a requisite number of impulses arriving synchronously (Joseph and Hyson, 1993), a sustained level of NM neuronal activity might be important for NL neurons to effectively function as coincidence detectors.

The outward current also enhances the ability of NM neurons to phase-lock. As was postulated for bushy cells (Oertel, 1983; Wu and Oertel, 1984; Manis and Marx, 1991), the rapid repolarization of both the subthreshold and suprathreshold voltage responses ensures that discrete events remain well segregated during acoustic stimulation. In addition, because the outward current deactivated rapidly, accumulation of activation during the train was relatively small. Thus, the latencies of the evoked action potentials did not systematically vary throughout the train. In contrast, pyramidal neurons, which lack strong outward rectification and have conductances with slow kinetics (Schwindt et al., 1988), could not phase-lock reliably. Interestingly, stellate cells in the mammalian AVCN also lack strong outward rectification (Manis and Marx, 1991) and do not exhibit reliable phase-locking (Pfeiffer, 1966).

Strong outward rectification would be unfavorable for ncurons like layer $\mathrm{V}$ pyramidal cells that fire in proportion to steadily applied current. The amplitudes of the unitary synaptic potentials in such cell types are typically on the order of hundreds of microvolts (cf. Cope et al., 1987; Kang et al., 1988; Thomson et al., 1988; Sayer et al., 1989) as compared to $20 \mathrm{mV}$ for $\mathrm{NM}$ neurons (Hackett et al., 1982; Jackson and Parks, 1982). Unlike in NM neurons, temporal summation of synaptic potentials is essential for firing in those neurons and some have ionic conductances that prolong the decay of synaptic potentials (Stafstrom et al., 1985; Thomson et al., 1988).

It is likely that the outward current described here, or some variant of it, will be found predominantly in neurons that must reliably transmit precise temporal information. For example, type I spiral ganglion cells, the first-order neurons of the auditory pathway, also have a rapidly activating outward current with a threshold near resting potential (Santos-Sacchi, 1993). The principal neurons of the rat medial nucleus of the trapezoid body (MNTB), which are innervated by afferents from bushy cells, probably also have a similar outward current. MNTB principal neurons exhibit 4-AP-sensitive outward rectification and fire repetitively to sinusoidal but not to sustained stimuli (Banks and Smith, 1992). Neurons of the avian and mammalian interaural time coding pathways are highly specialized: for accurate sound localization, they must process temporal information encoded in rapidly occurring inputs with a time resolution of microseconds (Carr and Konishi, 1990). It will be of interest to examine if a similar current exists in other neural systems that also require precise analysis of temporal information.

\section{References}

Banks MI, Smith PH (1992) Intracellular recordings from neurobiotinlabeled cells in brain slices of the rat medial nucleus of the trapezoid body. J Neurosci 12:2819-2837.

Boord RL, Rasmussen GL (1963) Projection of the cochlear and lagenar nerves on the cochlear nuclei of the pigeon. J Comp Neurol 120:463-475.

Carr CE, Konishi M (1990) A circuit for detection of interaural time differences in the brain stem of the barn owl. J Neurosci 10:32273246.

Cope TC, Fetz EE, Matsumura M (1987) Cross-correlation assessment of synaptic strength of single Ia fibre connections with triceps surae motoneurones in cats. J Physiol (Lond) 390:161-188.

Edwards F, Konnerth A, Sakmann B, Takahashi T (1989) A thin slice preparation for patch clamp recordings from synaptically connected neurones of the mammalian central nervous system. Pfluegers Arch 414:600-612.

Goldberg JM, Brown PB (1969) Response of binaural neurons of dog superior olivary complex to dichotic tonal stimuli: some physiological mechanisms of sound localization. J Neurophysiol 32:613-636.

Hackett JT, Jackson H, Rubel EW (1982) Synaptic excitation of the second and third order auditory neurons in the avian brain stem. Neuroscience 7:1455-1469.

Hodgkin AL, Huxley AF (1952) The dual effect of membrane potential on sodium conductance in the giant axon of Loligo. J Physiol (Lond) 116:497-506.

Hugues M, Romey G, Duval D, Vincent JP, Lazdunski M (1982) Apamin as a selective blocker of the calcium dependent potassium channel in neuroblastoma cells: voltage-clamp and biochemical characterization of the toxin receptor. Proc Natl Acad Sci USA 79:13081312.

Jackson H, Parks TN (1982) Functional synapse elimination in the developing avian cochlear nucleus with simultaneous reduction in cochlear nerve branching. J Neurosci 2:1736-1743.

Jhaveri S, Morest DK (1982) Neuronal architecture in nucleus magnocellularis of the chicken auditory system with observations on nucleus laminaris: a light and electron microscope study. Neuroscience 8:809-836.

Joseph AW, Hyson RL (1993) Coincidence detection by binaural neurons in the chick brain stem. J Neurophysiol 69:1197-1211.

Kang Y, Endo K, Araki T (1988) Excitatory synaptic actions between pairs of neighboring pyramidal tract cells in the motor cortex. J Neurophysiol 59:636-647. 
Manis PB, Marx SO (1991) Outward currents in isolated ventral cochlcar nucleus neurons. J Neurosci 11:2865-2880.

Manley GA, Kaiser A, Brix J, Gleich O (1991) Activity patterns of primary auditory-nerve fibres in chickens: development of fundamental properties. Hearing Res 57:1-15.

Miller C, Moczydlowski E, Latorre R, Phillips M (1985) Charybdotoxin, a protein inhibitor of single $\mathrm{Ca}^{2+}$-activated $\mathrm{K}^{+}$channels from mammalian skeletal muscle. Nature 313:316-318.

Oertel D (1983) Synaptic responses and electrical properties of cells in brain slices of the mouse anteroventral cochlear nucleus. J Neurosci 3:2043-2053.

Overholt EM, Rubel EW, Hyson RL (1992) A circuit for coding interaural time differences in the chick brainstem. J Neurosci 12:16981708.

Parks TN, Rubel EW (1975) Organization and development of brain stem auditory nuclei of the chicken: organization of projections from n. magnocellularis to $n$. laminaris. J Comp Neurol 164:435-448.

Pfeiffer RR (1966) Classification of response patterns of spike discharges for units in the cochlear nucleus: tone-burst stimulation. Exp Brain Res 1:220-235.

Raman IM, Trussell LO (1992) The kinetics of the response to glutamate and kainate in neurons of the avian cochlear nucleus. Neuron 9:173-186.

Reyes AD, Fetz EE (1993a) Two modes of interspike interval shortening by brief transient depolarizations in cat neocortical neurons. $\mathrm{J}$ Neurophysiol 69:1661-1672.

Reyes AD, Fetz EE (1993b) Effects of transient depolarizing potentials on the firing rate of cat neocortical neurons. J Neurophysiol 69:16731683.

Reycs AD, Hyson RL, Rubcl EW (1991) Electrophysiological properties of neurons in the chick nuclei magnocellularis and laminaris. Soc Neurosci Abstr 17:446.

Reyes AD, Spain WJ, Rubel EW (1992) Mechanism underlying the response of neurons in the chick $\mathrm{n}$. magnocellularis to stimulus trains. Soc Neurosci Abstr 18:151.

Rose JE, Brugge JF, Anderson DJ, Hind JE (1967) Phase-locked response to low-frequency tones in single auditory nerve fibers of the squirrel monkey.

Rubel EW, Parks TN (1975) Organization and development of the brain stem auditory nuclei of the chicken: tonotopic organization of n. magnocellularis and n. laminaris. J Comp Neurol 164:411-434.
Sachs MB, Sinnott JM (1978) Responses to tones of single cells in nucleus magnocellularis and nucleus angularis of the redwing blackbird (Agelaius phoeniceus). J Comp Physiol 126:347-361.

Santos-Sacchi J (1993) Voltage-dependent ionic conductances of type I spiral ganglion cells from the guinea pig inner ear. J Neurosci 13 : 3599-3611.

Sayer RJ, Redman SJ, Andersen P (1989) Amplitude fluctuations in small EPSPs recorded from CAl pyramidal cells in the guinea pig hippocampal slice. J Neurosci 9:840-850.

Schwindt PC, Spain WJ, Foehring RC, Stafstrom CE, Chubb MC, Crill WE (1988) Multiple potassium conductances and their functions in neurons from cat sensorimotor cortex in vitro. J Neurophysiol 59: 424-449.

Spain WJ, Schwindt PC, Crill WE (1991) Two transient potassium currents in layer $\mathrm{V}$ pyramidal neurones from cat sensorimotor cortex. J Physiol (Lond) 434:591-607.

Stafstrom CE, Schwindt PC, Chubb MC, Crill WE (1985) Properties of persistent sodium conductance and calcium conductance of layer $\mathrm{V}$ neurons from cat sensorimotor cortex in vitro. J Neurophysiol 53: 153-169.

Sullivan WE, Konishi M (1984) Segregation of stimulus phase and intensity coding in the cochlear nucleus of the barn owl. J Neurosci 4:1787-1799.

Thomson AM, Girdlestone D, West DC (1988) Voltage-dependent currents prolong single-axon postsynaptic potentials in layer III pyramidal neurons in rat neocortical slices. J Neurophysiol 60:18961907.

Trussell LO, Zhang S, Raman IM (1993) Desensitization of AMPA receptors upon multi-quantal neurotransmitter release. Neuron 10 : 1185-1196.

Warchol ME, Dallos P (1990) Neural coding in the chick cochlear nucleus. J Comp Physiol 166:721-734.

Wu SH, Oertel D (1984) Intracellular injection with horseradish peroxidase of physiologically characterized stellate and bushy cells in slices of mouse anteroventral cochlear nucleus. J Neurosci 4:15771588 .

Young SR, Rubel EW (1983) Frequency-specific projections of individual neurons in chick brainstem auditory nuclei. J Neurosci 3:13731378. 